\title{
FEATURE \\ Effectiveness of jatropha barriers as a soil and water conservation technology to rehabilitate gullies in northern Ethiopia
}

\author{
Albrecht Ehrensperger, Simon Bach, Hanspeter Liniger, Brigitte Portner, and Habtamu Ayele
}

J

atropha (Jatropha curcas L.), a perennial oil-producing shrub, has been promoted in many parts of subSaharan Africa in recent years, with the aim of producing biofuels, developing rural areas, and providing alternative income opportunities (Francis et al.2005). Researchers largely agree that jatropha is suited for rehabilitating degraded land, as it improves microbial activity, available nutrients, and water holding in soils (Wani et al. 2012). The basic pattern of its root structure is believed to control soil erosion (Achten et al. 2007), although in drylands limited water availability has negative effects on jatropha root growth and overall performance (Krishnamurthy et al. 2012). Nonetheless, only few studies investigate vegetative soil and water conservation technologies based on jatropha. Rare individual studies, such as the ones by Openshaw (2000) on hedges or by Kagamebga et al. (2011) on the half-moon technique in Burkina Faso, demonstrate that jatropha can, in different ways, successfully be used for soil and water conservation.

In the Ethiopian Highlands, land degradation is a major concern, and the control and rehabilitation of gullies pose a particular challenge. Efforts to conserve soil and water have been made for a long time and at a large scale (Dale 2010). However, farmers often lack incentives to build and maintain barriers and structures, which involve large investment and maintenance costs (Hurni et al. 2010). From this perspective, vegetative measures, such as

Albrecht Ehrensperger is head of the Thematic Cluster Innovations for Sustainable Development Centre for Development and Environment (CDE), University of Bern, Bern, Switzerland. Simon Bach is a specialist in geoinformatics at the City of Bern, Bern, Switzerland. Hanspeter Liniger is senior research scientist coordinator of the World Overview of Conservation Approaches and Technologies (WOCAT), Bern, Switzerland, and Brigitte Portner is a PhD candidate at CDE, University of Bern, Bern, Switzerland. Habtamu Ayele is planning, monitoring, and evaluation coordinator at food for the Hungry, Ethiopia.

\section{Figure 1}

Satellite view of the Tullu lyensa and Dodota watersheds. Features include land cover, drainage line status, and types of conservation barriers (adapted from Bach [2012]).

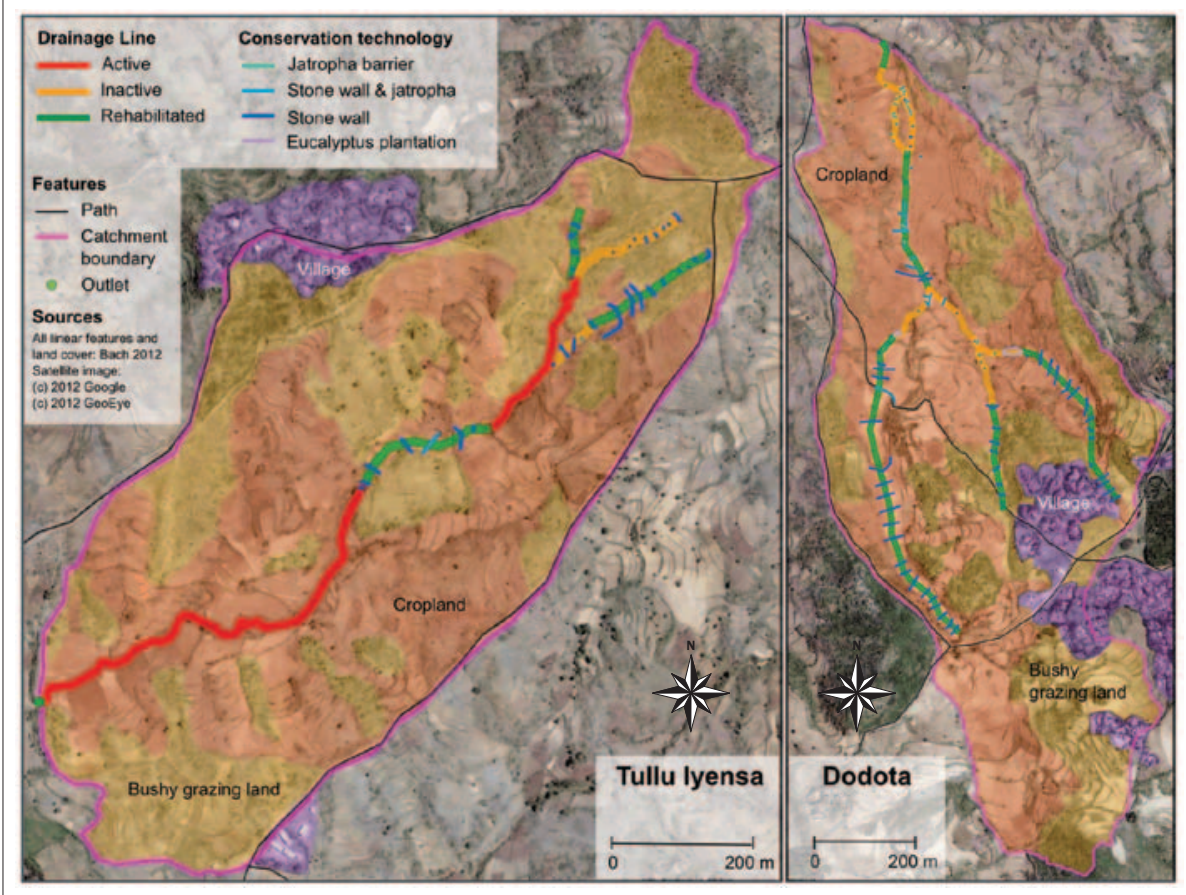

hedges, seem particularly attractive, as they offer a greater variety of products such as fruits or oil seeds (Hurni et al. 2008). These additional benefits might constitute an incentive for establishing such measures, especially in badly degraded and unproductive gullies.

Jatropha has been known in Ethiopia for approximately four decades. It is found mainly in the northeastern parts of the country, where it is grown as a live fence and for a variety of other uses. Its seeds and oil are sometimes used for lighting in households. The oil cake is processed into fertilizer, and various parts of the plant are used for medical treatment (Bach 2012; Nezir 2010). Among a number of other technologies, farmers have recently started using jatropha for soil and water conservation along hillsides. Based on this local initiative, the agricultural office in Bati, where this study was conducted, began around 10 years ago to promote jatropha for stabilizing gullies in heavily degraded farming areas. However, an assessment of the performance-in terms of ease of implementation, range of application, and soil retention potential - and impacts-in terms of improved soil fertility, yields, and food security - of this conservation measure has been lacking thus far.

This article investigates the suitability of soil and water conservation barriers based on jatropha for rehabilitating or preventing gullies and compares these jatropha barriers with traditional stone wall constructions in Bati, northern Ethiopia. It considers positive and negative socioeconomic and environmental side effects, the amount of work required for barrier construction and maintenance, and chances for spontaneous dissemination within Bati and beyond.

\section{STUDY AREA AND ASSESSMENT}

Data were collected in April of 2011 in two small watersheds, Tullu Iyensa and Dodota, in the Bati district of Amhara Region, Ethiopia (figure 1). Both watersheds are located at an altitude of 
approximately $1,600 \mathrm{~m}(5,249 \mathrm{ft})$ and receive an annual rainfall of around 750 $\mathrm{mm}$ (30 in), concentrated mainly in the months of July and August.

Stone walls and jatropha barriers were described and assessed using the questionnaires of the World Overview of Conservation Approaches and Technologies (WOCAT 2014). This approach combines talks with land users, own observations in the field, and crosschecking with local experts (Liniger et al. 2008a and 2008b). The questionnaires are later used to establish fact sheets for each conservation technology, and each fact sheet undergoes quality checking. The WOCAT approach is standardized, it is used worldwide, and its database has recently been endorsed by the United Nations Convention to Combat Desertification. The study also included a mapping and spatial analysis component. Watershed boundaries, land use types, locations of jatropha barriers and stone walls, and drainage lines and their degradation statuses were mapped using a global positioning system (GPS) receiver. Subsequently, slope gradients of drainage lines and spatial correlations between conservation measures, slope gradients, and degradation status were assessed with geographic information system (GIS) software. Finally, a group discussion was organized with several farmers in the town of Bati to discuss aspects of land degradation, conservation technologies, and the potential of jatropha as a multipurpose plant, and informal talks were held with the district agricultural advisor to cross-check information received from land users and to get additional information on the sustainable land management strategy of the agricultural office of Bati.

\section{CONSERVATION TECHNOLOGIES}

Stone wall barriers are the most widely used structures to rehabilitate gullies in the two watersheds: there are 85 of them (63\% of all barriers), totaling a length of 1,190 $\mathrm{m}(3,904 \mathrm{ft})$ in Tullu Iyensa and $479 \mathrm{~m}$ $(1,572 \mathrm{ft}$ ) in Dodota (table 1; figures 2 and $3)$. Their main technical functions are to control concentrated runoff, reduce slope angle and length, increase water storage in the soil, and trap sediments in preparation for later use of the land for crop production. In Bati, stone wall barriers consist of two separate walls of fairly large stones crossing the gully approximately $1 \mathrm{~m}(3 \mathrm{ft})$ apart from each other, each set in a trench of about $30 \mathrm{~cm}$ (12 in) depth to ensure stability. The gap between the walls is filled with gravel, small stones, or soil, depending on availability. These stone walls can reach heights of $5 \mathrm{~m}(16 \mathrm{ft})$ and are bent downhill on the sides to improve their ability to withstand water flow and the pressure from accumulating alluvial soil.
Jatropha barriers for soil and water conservation are grown along hillsides and across gullies (figures 2 and 4). Their main technical functions are identical to those of stone walls (see above). This vegetative measure is not yet very popular in either of the two watersheds. Only 27 jatropha barriers were implemented $(20 \%$ of all barriers), totaling a length of $103 \mathrm{~m} \mathrm{(338}$ $\mathrm{ft})$ in Dodota and only $4 \mathrm{~m}$ (13 ft) in Tullu Iyensa (a single barrier in an inactive gully; see table 1). The usual propagation method is from cuttings, which are easily accessible since jatropha is widespread in the region.

\section{Figure 2}

Sketch of (a) a stone wall and (b) a jatropha barrier. Farmers use these technologies for soil and water conservation along hillsides and in gullies (Bach 2012).

(a)

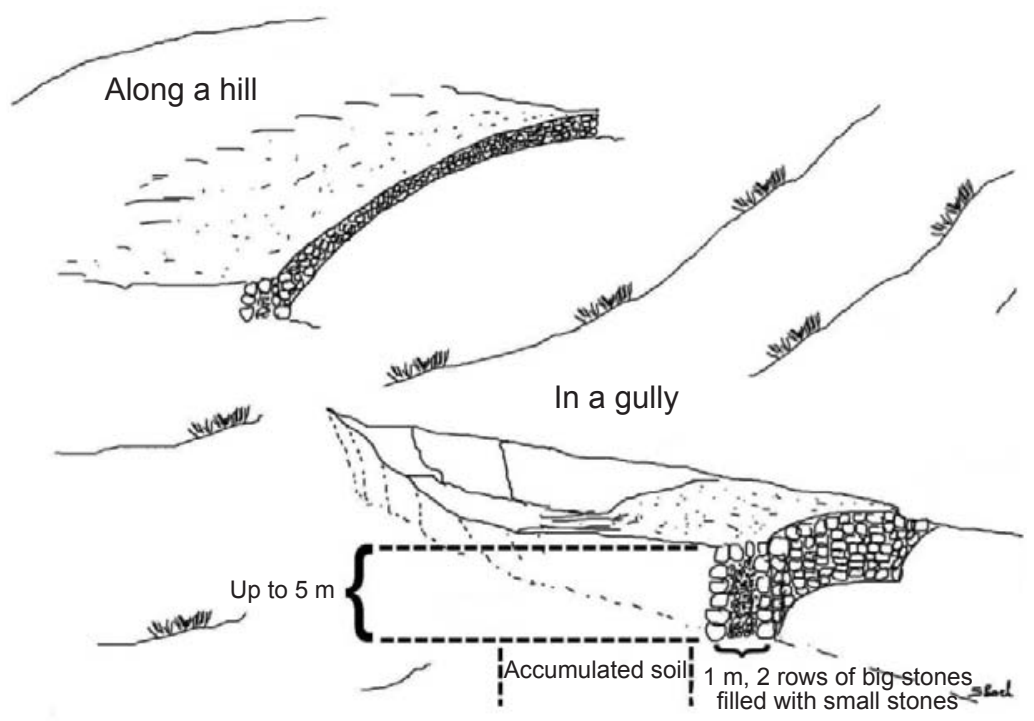

(b)

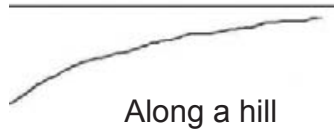




\section{Table 1}

Summary of soil and water conservation measures in each watershed for each type of gully.

\begin{tabular}{|c|c|c|c|c|c|c|c|c|c|c|}
\hline \multirow[b]{2}{*}{ Location } & \multicolumn{2}{|l|}{ Type of gully } & \multicolumn{2}{|c|}{ Stone walls } & \multicolumn{2}{|c|}{ Jatropha } & \multicolumn{2}{|c|}{ Combined } & \multicolumn{2}{|c|}{ All structures } \\
\hline & Length $(\mathrm{m})^{*}$ & $\%$ & $\mathrm{n}$ & Length (m) † & $\mathrm{n}$ & Length $(m) \dagger$ & $\mathrm{n}$ & Length $(m) \dagger$ & $\mathrm{n}$ & Length $(\mathrm{m}) \mathrm{t}$ \\
\hline \multicolumn{11}{|l|}{ Dodota } \\
\hline Active & 0 & 0 & 0 & 0 & 0 & 0 & 0 & 0 & 0 & 0 \\
\hline Inactive & 863 & 35 & 3 & 10 & 22 & 77 & 12 & 85 & 37 & 172 \\
\hline Rehabilitated & 1,597 & 65 & 46 & 1,180 & 4 & 26 & 10 & 220 & 60 & 1,426 \\
\hline Total & 2,460 & 100 & 49 & 1,190 & 26 & 103 & 22 & 305 & 97 & 1,598 \\
\hline \multicolumn{11}{|l|}{ Tullu Iyensa } \\
\hline Active & 987 & 55 & 0 & 0 & 0 & 0 & 0 & 0 & 0 & 0 \\
\hline Inactive & 282 & 16 & 12 & 90 & 1 & 4 & 0 & 0 & 13 & 94 \\
\hline Rehabilitated & 524 & 29 & 24 & 389 & 0 & 0 & 1 & 38 & 25 & 427 \\
\hline Total & 1,793 & 100 & 36 & 479 & 1 & 4 & 1 & 38 & 38 & 521 \\
\hline
\end{tabular}

* Length $(\mathrm{m})=$ length in meters of the drainage line.

† Length $(m)=$ length in meters of conservation barrier.

These cuttings are harvested towards the end of the rainy season and planted during the dry season, when the workload of farmers is low. They are planted as closely as possible to each other to minimize gaps, which are filled with small stones, branches, or litter. Once the cuttings have developed roots, they withhold alluvial soil washed against them during the rainy season. Despite the fact that cuttings only produce 3 to 5 lateral roots and do not develop a vertical tap root, which would increase their stability and resistance to drought, freshly rooted cuttings are flexible enough to bend and withstand pressure in a high water flow. Litter and transported material accumulate in the barrier, and as the plants grow, the gaps between stems are closed, enabling siltation within and upslope from the barrier. Jatropha barriers can withhold alluvial soil up to a height of around 1 $\mathrm{m}(3 \mathrm{ft})$; beyond this height, stems tend to be too thin, and lateral branches as well as foliage do not provide sufficient withholding capacity.

\section{Figure 3}

Sequence of small stone walls in a steep section of an inactive gully (Bach 2012).

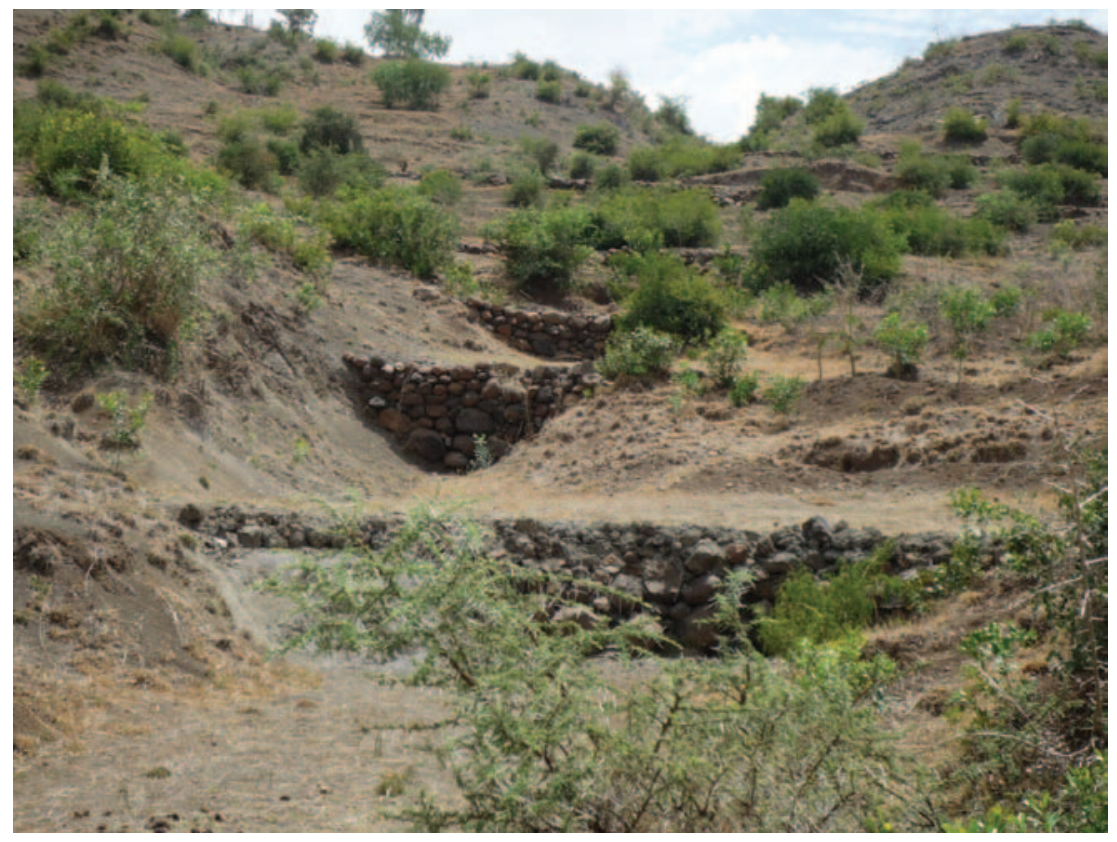

Sometimes jatropha barriers are combined with stone walls, in which case jatropha is usually planted in front or on top of the walls. Farmers use this technology to enhance the stability of stone walls. Although the effectiveness of this particular technology has not been scientifically assessed, other examples show that structural and vegetative measures are often successfully combined by land users (Liniger and Critchley 2007). In the two watersheds, the combination of stone walls and jatropha had so far only been applied in 23 cases ( $17 \%$ of all barriers). However, these combined barriers are usually longer than jatropha barriers; there are $305 \mathrm{~m}$ $(1,000 \mathrm{ft})$ of combined barriers in Dodota and $38 \mathrm{~m}$ (125 ft) in Tullu Iyensa (table 1).

\section{PERFORMANCE OF CONSERVATION TECHNOLOGIES}

Figure 1 and table 1 show that the effect of soil and water conservation on gully rehabilitation is striking. Wherever barriers are in place, gullies have become inactive or been rehabilitated; where barriers are missing, gullies have remained active. The difference between the two catchments is obvious: in Dodota, where there are almost twice as many barriers (39) per kilometer of drainage line than in Tullu Iyensa (21), there is no active gully left. Table 1 further reveals that stone walls strongly prevail in fully rehabilitated gullies (70 stone walls, or $82 \%$ of all barriers in rehabilitated gullies), while jatropha barriers are more numerous in inactive gullies (23 jatropha barriers, or $46 \%$ of all barriers in inactive gullies). This 


\section{Figure 4}

Sequence of small jatropha barriers in an inactive gully (Bach 2012).

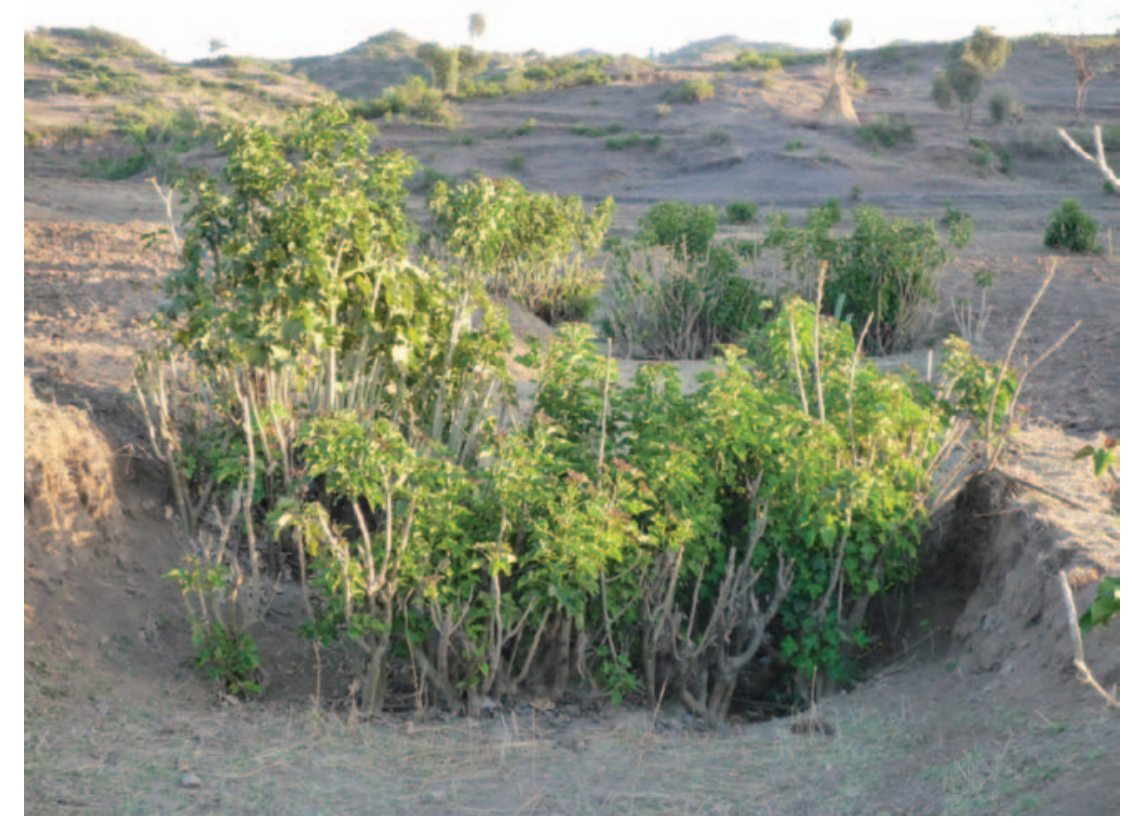

difference is not the result of jatropha barriers performing less well; rather, it can be explained by the history of soil and water conservation in Bati and the long time it takes for a gully to become fully rehabilitated. Land users reported that stone walls have been used as conservation structures in the area for several generations, whereas the local agricultural office only started promoting jatropha for gully rehabilitation about 10 years ago. Hence, it is likely that most inactive gully sections treated with jatropha barriers will eventually become fully rehabilitated.

A topographic analysis based on 48 elevation points gathered along the central drainage line of the Dodota Watershed revealed that the average slope of sections conserved with stone walls is $12.6 \%$ (median 10.9; sd 9.2), while jatropha and mixed barriers are found in sections with an average slope of $5.8 \%$ (median 4.3; sd 5.8). This is because jatropha barriers can only retain soil up to a height of 1 $\mathrm{m}(3 \mathrm{ft})$. This means that in steep sections of the drainage line the horizontal spacing between barriers would need to be reduced considerably, leading to significant loss of land for agricultural use and to increased competition with food crops for sunlight and water.

\section{POSITIVE AND NEGATIVE SIDE EFFECTS}

Land users highly valued both types of barriers for enabling them to reclaim agricultural land inside gullies. This land is generally well suited for crop production: it consists of level and fertile alluvial soil, and the conservation barriers help to retain soil moisture. Additionally, jatropha barriers provide shade and act as windbreaks, reducing evapotranspiration in adjacent cropland and thereby increasing yield potentials. These positive side effects are perceived as important contributions toward increasing harvest reliability, food security, and household incomes. Moreover, land users highly appreciated the positive impact both types of barriers have on surface runoff, mentioning that they help to reduce flood water flow and thereby prevent damage to neighbors' fields or to public infrastructure. Increased water availability was also mentioned as an important positive side effect, as both types help to recharge the groundwater table and facilitate water harvesting. Finally, land users mentioned that jatropha contributes to habitat diversity, especially in terms of increasing beneficial species in the area.

During the group discussion in Bati, the participating land users reported that the two main negative side effects of both barriers are (1) the risk of increased pests, especially rodents and insects, as they use both structures as a habitat; and (2) reduced sediment yields on downhill fields. Furthermore, both barriers can lead to waterlogging, which can negatively affect plant growth. Jatropha competes for sunlight and water with nearby crops, making it necessary to prune them regularly; this, in turn, strongly reduces the potential seed yields from jatropha shrubs. Indeed, land users reported that jatropha barriers used for gully rehabilitation are economically irrelevant for biofuel production. Competition for water and light increases with slope, because steepness requires reducing horizontal spacing between barriers; for this reason, farmers prefer stone walls in steep sections of the drainage line.

\section{LABOR INVESTMENT AND ADOPTION RATES}

The workload for establishing conservation barriers was calculated on the basis of the information gathered with the WOCAT questionnaires, which specifically assess this aspect. While the materials for constructing stone walls and jatropha barriers are readily available and need not be purchased, investments in terms of labor vary considerably between barrier types. Establishing jatropha barriers includes preparing the cuttings ( $40 \%$ of workload), planting them (40\% of workload), and filling the gaps with litter (20\% of workload). In constructing stone walls, the preparation of stones accounts for $40 \%$ of the workload, digging the foundations for about $20 \%$, and building the wall for about $40 \%$.

Estimates made during joint fieldwork with two land users in each watershed showed that $100 \mathrm{~m}$ (328 ft) of jatropha barrier can be established with an investment of 6 workdays; by contrast, around 230 workdays (almost 40 times more)

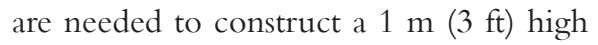
stone wall of the same length. This huge difference in workload is the main reason why land users rate the short-term cost/ benefit ratio of jatropha barriers (during and immediately after construction) as only slightly negative, whereas that of stone walls is perceived as very negative. Similarly, the higher workload for the maintenance of stone walls compared to 
jatropha barriers is reflected in a positive assessment of the long-term cost to benefit ratio of the former and a very positive cost to benefit ratio of the latter.

The difference in labor needed for establishing and maintaining the two types of barriers has a significant impact on their adoption by smallholders. During interviews land users reported that all jatropha barriers in both catchments had been constructed voluntarily, with no external material support. At first, the local agricultural office had actively promoted the technology; later it had spread spontaneously from farmer to farmer. Land users mentioned a strong trend towards spontaneous adoption of jatropha barriers in the region, and attributed this to the small amount of work needed to establish and maintain them. In contrast, land users reported that all stone walls had been constructed with material support from the local agricultural office. Although farmers have started to build structures on their own initiative, they usually seek external support to cover at least part of the costs. Accordingly, there is only a moderate trend towards spontaneous adoption of this technology by smallholders, mainly due to the heavy labor investment required.

\section{CONCLUSIONS}

This study has shown that jatropha barriers are a cheap and effective soil and water conservation technology for gully rehabilitation in the study area. Their advantages include the comparatively small labor investments required for their construction and maintenance, as well as their additional function as windbreaks that help to reduce water loss by evaporation in semiarid areas. Drawbacks of jatropha barriers include the fact that their soil retention ability is limited to a height of $1 \mathrm{~m}$ barrier $^{-1}$ (3 ft barrier $^{-1}$ ); in the two catchments analyzed, this has restricted their use to sections of the drainage line with an average slope of around $6 \%$. Moreover, if not pruned, jatropha barriers compete for moisture and light with nearby crops, and offer a potential habitat for rodents. Nonetheless, the advantages of jatropha barriers seem to prevail. Their low cost makes them particularly interesting for smallholders, who play a critical role in maintaining ecosystems and providing food, feed, fuel, and fiber.

Discussions with land users and local experts clearly indicated that, at least at the present stage, the potential of jatropha barriers as a source of energy is negligible. Though yields in jatropha hedges vary greatly, an average of $1 \mathrm{~kg}$ seeds $\mathrm{m}^{-1}(2.02$ $\mathrm{lb}$ seeds $\mathrm{yd}^{-1}$; i.e., approximately $0.2 \mathrm{~L}$ [7 $\mathrm{oz}$ ] of jatropha oil) of hedge is realistic (Ehrensperger et al. 2013). Considering the relatively short lengths of gully rehabilitation barriers, yields obtained would currently be insignificant and harvesting inefficient due to the spatial arrangement of barriers. Ehrensperger et al. (2012) calculated that substituting paraffin for lighting with jatropha oil from hedges around smallholders' plots does not provide significant economic advantage to farmers; thus it is expected that the economic performance of jatropha barriers in gullies would be even less favorable.

A number of questions still need to be clarified with a view to further dissemination of this soil and water conservation technology:

1. The suitability of jatropha barriers for full rehabilitation of gullies could not be assessed due to the insufficient time span between their construction and the fieldwork for this study. Even though it is assumed that their performance is comparable to that of stone walls, a comparative study in a few years in the same watersheds could help to clarify this question.

2. Even though land users reported that jatropha barriers have no economic potential as biofuel feedstock, this option should not simply be dismissed. Selective pruning and various intercropping options should be tested to further assess jatropha's potential as a multifunctional plant for combined soil and water conservation and biofuel production.

3. It would be interesting to compare jatropha barriers with other vegetative gully rehabilitation measures. Such a comparative assessment could be done on the basis of the WOCAT database.

4. The potential for scaling out jatropha barriers to other regions of Ethiopia or East Africa has not yet been assessed.
Further research on jatropha barriers in areas with different cropping systems, soil characteristics, and climatic patterns is therefore recommended.

\section{REFERENCES}

Achten, W.M.J., B. Reubens, W. Maes, E. Mathijs, L. Verchot, and V.P. Singh. 2007. Root architecture of the promising bio-diesel plant jatropha. Communication in Agricultural and Applied Biological Sciences 72(1), Leuven, Belgium. Ghent. http://www.biw.kuleuven.be/lbh/lbnl/ forecoman/eng/publications.asp.

Achten, W.M.J., W.H. Maes, R. Aerts, L. Verchot, A. Trabucco, E. Mathijs, V.P. Singh, and B. Muys, B. 2010. Jatropha: From global hype to local opportunity. Journal of Arid Environments 74:164-165.

Bach, S. 2012. Potentials and limitations of Jatropha curcas as a multipurpose crop for sustainable energy supply and soil and water conservation. A case study in Bati, Ethiopia, using the WOCAT approach. Master's thesis. Bern: University of Bern.

Dale, D.D. (Ed.). 2010. Sustainable land technologies and approaches in Ethiopia. Addis Abeba, Ethiopia: Ministry of Agriculture and Rural Development.

Ehrensperger, A., B. Portner, and B. Kiteme. 2012. Potentials and limitations of Jatropha curcas for rural energy supply in East Africa: A case study based comparative assessment in Ethiopia, Kenya, and Tanzania. Paper presented at Tech4Dev 2012 Conference in Lausanne (Switzerland).

Ehrensperger, A., M. Wörgetter, V. Moraa, and A. Sonnleitner. 2013. Can Jatropha Improve the Energy Supply of Rural Households in Africa? Jatropha Facts Series, No. 3(2013):3-6. http://www. cde.unibe.ch/Pages/Bioenergy-in-Africa.aspx.

Francis, G., R. Edinger, and K. Becker. 2005. A concept for simultaneous waste land reclamation, fuel production, and socio-economic development in degraded areas in India: Need, potential and perspectives of Jatropha plantations. Natural Resources Forum 29:12-24.

Hurni, H., K. Herweg, B. Portner, and H. Liniger. 2008. Soil erosion and conservation in global agriculture. In Land Use and Soil Resources, eds.A.K. Braimoh, and P.L.G.Vlek, 41-71. Netherlands: Springer.

Hurni, H., S. Abate, A. Bantider, B. Debele, E. Ludi, B. Portner, B. Yitaferu, and G. Zeleke. 2010. Land degradation and sustainable land management in the Highlands of Ethiopia. In Global Change and Sustainable Development:A Synthesis of Regional Experiences from Research Partnerships. Perspectives of the Swiss National Centre of Competence in Research (NCCR) NorthSouth, eds. H. Hurni and U. Wiesmann (with an 
international group of coeditors), 187-207. Bern: University of Bern, Vol 5. Geographica Bernensia. Kagamèbga, W.F., A. Thiombiano, S. Traoré, R. Zougmoré, and J.I. Boussim. 2011. Survival and growth responses of Jatropha curcas L. to three restoration techniques on degraded soils in Burkina Faso. Annals of Forest Research 54(2):171-184. http:// www.editurasilvica.ro/afr/54/2/kagambega.pdf.

Krishnamurthy, L., M. Zaman-Allah, S. Marimuthu, S.P. Wani, and A.V.R. Kesava Rao. 2012. Root growth in jatropha and its implications for drought adaptation. Biomass \& Bioenergy 39:247-252. http:// dx.doi.org/10.1016/j.biombioe.2012.01.015.

Liniger, H.P., and W. Critchley. 2007. Where the land is greener: Case studies and analysis of soil and water conservation initiatives worldwide. Bern: Centre for Development and Environment.

Liniger, H.P., G. Schwilch, M. Gurtner, R. Mekdaschi Studer, C. Hauert, G. van Lynden, and W. Critchley. 2008a. A framework for documentation and evaluation of sustainable land management: Technologies basic questionnaire. WOCAT (www.wocat.net), CDE Berne. http:// www.wocat.net/en/methods/case-study-assessment-qtqa/questionnaires.html.
Liniger, H.P., G. Schwilch, M. Gurtner, R. Mekdaschi Studer, C. Hauert, G. van Lynden, and W. Critchley. 2008b. A framework for documentation and evaluation of sustainable land management: approaches basic questionnaire. WOCAT, CDE, Berne. http://www.wocat.net/ en/methods/case-study-assessment-qtqa/questionnaires.html.

Nezir, Z., 2010. Farmers' indigenous knowledge in managing and using Jatropha curcas in Bati District, Oromiya Zone, Amhara Region. Master's thesis. Ethiopia: Haramaya University.

Openshaw, K. 2000. A review of Jatropha curcas: An oil plant of unfulfilled promise. Biomass \& Bioenergy 19:1-15.

Wani, S.P., G. Chander, K.L. Sahrawat, C.H. Srinivasa Rao, G. Raghvendra, P. Susanna, and M. Pavani. 2012. Carbon sequestration and land rehabilitation through Jatropha curcas (L.) plantation in degraded lands. Agriculture, Ecosystems \& Environment 161:112-120.

WOCAT (World Overview of Conservation Approaches and Technologies). 2014. World Overview of Conservation Approaches and Technologies. www.wocat.net. 